\title{
PROPOSTA DE APLICAÇÃO DO CICLO PDCA COMO FERRAMENTA DE APOIO AO GERENCIAMENTO DE PROCESSOS: ESTUDO DE CASO EM UMA OFICINA MECÂNICA LOCALIZADA NO MUNICÍPIO DO RIO DE JANEIRO
}

\author{
Roberta Anastácia Palermo Fernandes \\ Centro Universitário Estadual da Zona Oeste - UEZO \\ Avenida Manuel Caldeira de Alvarenga, 1203-Campo Grande-RJ, 23070-200 \\ roberta_anas@hotmail.com \\ Carolina Rodrigues Silva Ferreira Melo Dantas \\ Centro Universitário Estadual da Zona Oeste - UEZO \\ Avenida Manuel Caldeira de Alvarenga, 1203-Campo Grande-RJ, 23070-200 \\ carollina_mello@hotmail.com \\ Gabriel Henrique Fernandes \\ Centro Universitário Augusto Motta - UNISUAM \\ Avenida Cesário de Melo, 2541-Campo Grande-RJ, 23052-102 \\ gabrielhfernandes@hotmail.com \\ Marcos dos Santos \\ Instituto Militar de Engenharia -IME \\ Praça General Tibúrcio, 80 - Urca, Rio de Janeiro - RJ, 22290-270 \\ marcossantos@casnav.mar.mil.br
}

\section{RESUMO}

As Ferramentas da Qualidade são técnicas que auxiliam no aprimoramento da gestão de processos visando à eficiência dos mesmos, além de possibilitarem uma análise objetiva acerca dos fatos que atuarão como pilares para a tomada de decisão. O Ciclo PDCA possui suas etapas pautadas na melhoria contínua, contribuindo para o desenvolvimento constante dos processos organizacionais. $\mathrm{O}$ presente artigo trata da utilização do Ciclo PDCA, bem como das Ferramentas da Qualidade Brainstorming, Diagrama de Ishikawa, Plano de ação, Lista de verificação e fluxo de processos, objetivando o diagnóstico e a correção das não-conformidades que ocorrem em uma oficina mecânica situada no Rio de Janeiro. Os resultados obtidos indicam que a ausência de um padrão operacional é a principal razão para os elevados índices de retrabalho e insatisfação dos clientes quanto ao estado mecânico e físico de seus veículos.

Palavra-chave: Ferramentas da Qualidade; Gestão de Processos; Ciclo PDCA.

\begin{abstract}
The Quality Tools are techniques that help improve process management aiming at their efficiency, besides allowing an objective analysis about the facts that will act as pillars for decision making. The PDCA Cycle has its stages based on continuous improvement, contributing to the constant development of organizational processes. This article deals with the use of the PDCA Cycle, as well as Brainstorming Quality Tools, Ishikawa Diagram,
\end{abstract}


Action Plan, Checklist and Process Flow, aiming at diagnosing and correcting nonconformities that occur in a machine shop. located in Rio de Janeiro. The results indicate that the absence of an operating standard is the main reason for the high rework rates and customer dissatisfaction with the mechanical and physical condition of their vehicles.

Keywords: Quality tools; Processes management; PDCA cycle.

\section{Como Citar:}

FERNANDES, Roberta; DANTAS, Carolina; FERNANDES, Gabriel; SANTOS, Marcos. Proposta de aplicação do ciclo PDCA como ferramenta de apoio ao gerenciamento de processos: estudo de caso em uma oficina mecânica localizada no município do Rio de Janeiro. In: SIMPÓSIO DE PESQUISA OPERACIONAL E LOGÍSTICA DA MARINHA, 19., 2019, Rio de Janeiro, RJ. Anais [...]. Rio de Janeiro: Centro de Análises de Sistemas Navais, 2019.

\section{INTRODUÇÃO}

$\mathrm{Na}$ incessante busca pelo sucesso de seus produtos e serviços prestados, no cenário atual, as organizações vêm se tornando cada vez mais competitivas ao almejar um status de referencial no mercado no qual estão inseridas. O posicionamento de mercado e a demanda de uma empresa dependem da qualidade dos produtos e serviços oferecidos pela mesma aos seus clientes.

Para a implementação do sistema de gestão da qualidade são necessárias ferramentas que possibilitem a análise de fatos e suporte à tomada de decisão. Esses instrumentos são denominados ferramentas de gestão da qualidade. A utilização delas visa atingir um elevado grau de eficiência nas atividades que compõem um processo.

Segundo Slack (2009), implementar ferramentas da qualidade e detectar desperdícios tanto financeiros quanto de tempo de execução das atividades, no caso do estabelecimento em questão são fundamentais para a redução de erros e gargalos nas operações.

Ao iniciar um programa de qualidade dentro de uma empresa, esta deve estar preparada para enfrentar grandes mudanças e aceitar os desafios que serão gerados ao longo desta empreitada, que trará consigo não somente resoluções de problemas, mas também melhorias contínuas para a empresa em questão.

Diante do exposto, este estudo tem como finalidade a utilização do ciclo PDCA como base para a correção de falhas recorrentes na prestação de serviços de uma oficina mecânica automotiva, situada no Rio de Janeiro, que vem atravessando diversas intempéries em sua gestão de processos, tais como: elevado índice de retrabalho, insatisfações referentes à identificação de outros problemas mecânicos diferentes dos solicitados inicialmente e os consequentes prejuízos ao relacionamento com o cliente.

Deste modo, a mesma poderá traçar um plano de ação direcionado à redução da ocorrência destas falhas, reduzindo o dispêndio de recursos financeiros e de tempo com retrabalhos, além de aprimorar a qualidade dos serviços prestados ao atender às necessidades dos clientes, de maneira mais satisfatória. 


\section{SPOLM2O19}

XIX SIMPÓSIO DE PESQUISA OPERACIONAL E LOGISTICA DA MARINHA

\section{REFERENCIAL TEÓRICO}

\subsection{GESTÃo Da QUALIDADE}

Segundo Carpinetti (2012), a gestão da qualidade é o principal fator que impulsiona a produtividade e a competividade dos produtos e serviços de uma empresa

Para Toledo (2014), a efetividade no gerenciamento da qualidade só se torna possível através do comprometimento da alta administração com a qualidade dos produtos e serviços oferecidos, levando assim à necessidade de implementação de diretrizes que contribuam para o aperfeiçoamento contínuo de todo o sistema produtivo, que visem o treinamento de todos os colaboradores, a padronização e o controle dos processos desenvolvidos pela Organização.

\subsection{FERRAMENTAS DA QUALIDADE}

Segundo Campos (2004), as ferramentas qualidade auxiliam as organizações na busca e soluções de problemas, pois são técnicas de fácil execução e que demonstram efetividade na correção das falhas encontradas dentro dos sistemas produtivos, permitindo não somente o controle dos processos, mas também seu aperfeiçoamento e gerenciamento.

Existem diversas ferramentas da qualidade empregadas para solução e busca de problemas. Neste estudo as ferramentas que serão utilizadas são: Ciclo PDCA, Brainstorming, Diagrama de Ishikawa, $5 \mathrm{~W} 2 \mathrm{H}$, lista de verificação e fluxo de processos.

\subsubsection{Ciclo PDCA}

Segundo Lima (2006), o Ciclo PDCA é uma ferramenta da qualidade, que visa à melhoria contínua dos processos, pois permite a padronização, o controle e a eliminação de falhas dentro dos mesmos. Em vista disto, o PDCA é uma das ferramentas gerenciais mais utilizada pelas organizações para auxiliar na tomada decisões estratégicas.

Werkema (1995), afirma que é necessário o suporte de outras ferramentas qualidade para auxiliar suporte e coleta de informação para cada etapa a ser desenvolvida no ciclo. Segundo Junior (2008), o Ciclo PDCA é composto de quatro fases, que são elas:

- Plan (Planejamento): nesta etapa do ciclo são determinadas as metas a serem alcançadas, assim como seus respectivos tempos de alcance e recursos necessários para sua efetivação;

- Do (Execução): esta etapa ocorre posterior ao planejamento, e onde são postas em prática as ações planejadas;

- Check (Verificação): após a execução do planejamento, é feita a verificação dos resultados para averiguar se as metas estabelecidas foram alcançadas;

- Act (Ação): nesta etapa do ciclo é feita a correção dos efeitos indesejados e padronização dos processos executados.

\subsubsection{Brainstorming}

De acordo com Miguel (2001), o Brainstorming consiste em coletar e estimular ideias dos integrantes da reunião, onde cada um dos participantes, um por vez e continuadamente sem nenhuma preocupação crítica, dão suas ideias e opiniões até que se esgotem todas as possibilidades de ideias. Destina-se a superar as pressões da interação em favor da conformidade que retardam o desenvolvimento de alternativas criativas. Isso é obtido pela utilização de um processo de geração de ideias que incentive especificamente toda e qualquer alternativa suspendendo qualquer crítica a elas numa verdadeira "tempestade 
de ideias".

\subsubsection{Diagrama de Ishikawa}

O diagrama de Ishikawa, também conhecido como "espinha de peixe", recebeu esse nome devido ao seu criador, Kaoru Ishikawa e, segundo Roth (2011), é uma forma gráfica utilizada como metodologia para a análise e representação dos fatores de influência (causas) sobre um determinado problema (efeito). Com a utilização de Ishikawa é possível determinar os motivos dos problemas para solucioná-los da maneira mais eficiente possível.

Segundo Batista e Gois (2013) Os problemas podem ser resultante dos seus tipos de causas, classificadas da seguinte forma: método (a forma de como o trabalho é executado), medição (decisões ou medidas sobre o processo), máquina (a forma de operação), meio ambiente (o ambiente que está inserido), material (a matéria prima utilizada no processo) e mão-de-obra (a qualificação de quem executa os processos). O diagrama estruturado pode ser visto na Figura 1 a seguir.

Figura 1: Representação gráfica do Diagrama de Ishikawa

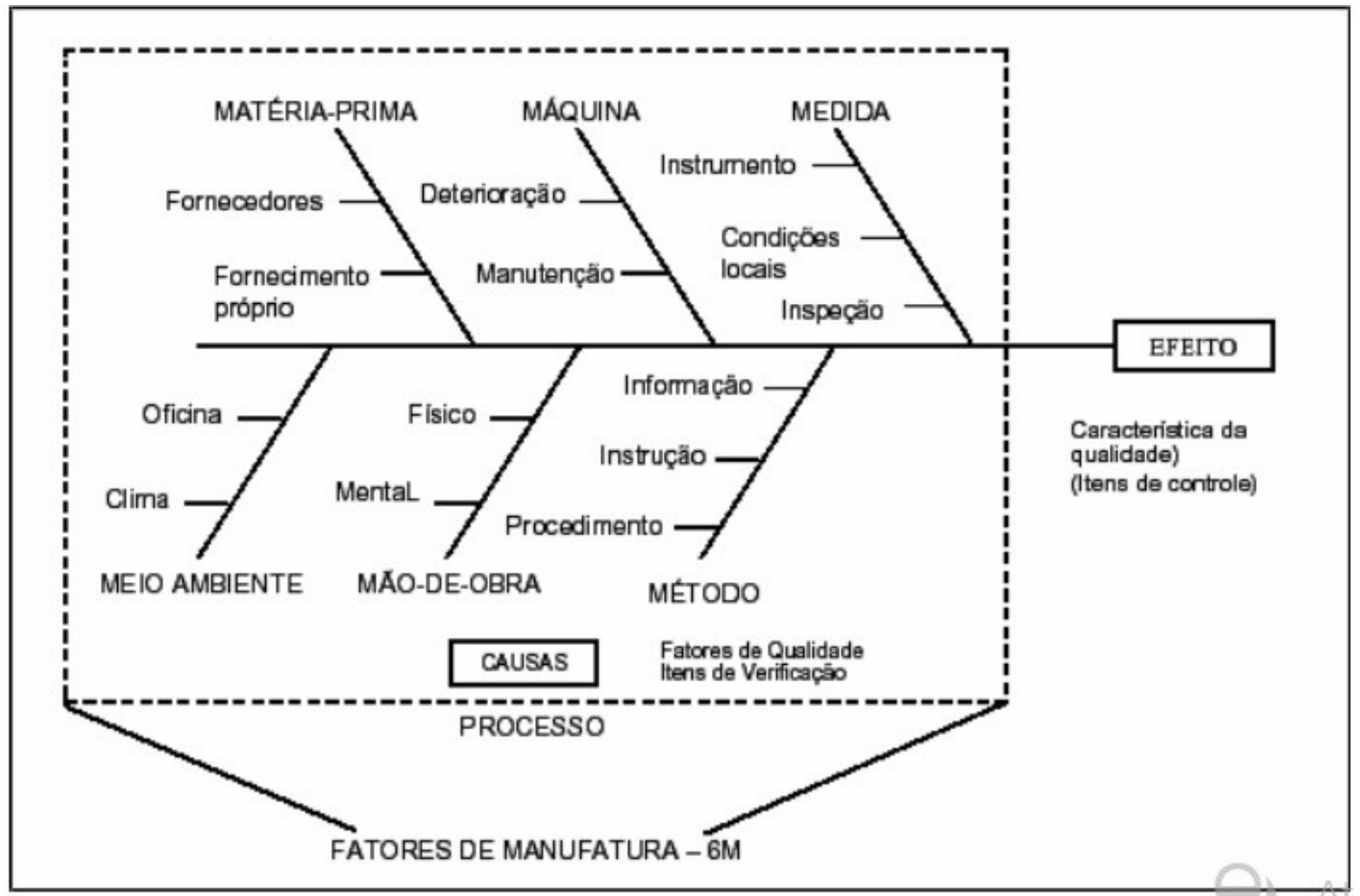

Fonte: Campos, 2004

\subsubsection{Plano de Ação (5W2H)}

Segundo Silveira et al. (2016) o 5W2H é uma metodologia onde há respostas para as atividades executadas pela organização, com períodos definidos e encarregado de funções que irão executar o processo, ainda é destacado pelo autor que esta metodologia pode ser avistada por meio da elaboração de uma tabela em forma de planilha, que é utilizada para 
levantar ações, que levarão ao cumprimento dos processos do controle da qualidade.

Para Lisbôa e Godoy (2012) esta ferramenta tem larga aplicabilidade, pois permite formalizar um plano de ação, onde será identificado e documentado as ações para que os objetivos gerenciais sejam alçados.

A elaboração do plano de ação é baseada em sete perguntas estrangeiras que estão representadas no Quadro 1 a seguir:

Quadro 1: Etapas de elaboração do Plano de Ação

\begin{tabular}{|l|l|l|l|}
\hline \multirow{4}{*}{$5 \mathbf{W}$} & What? & O quê? & Quais ações serão executadas? \\
\cline { 2 - 4 } & Who? & Quem? & Quem irá executar a ação? \\
\cline { 2 - 4 } & Where? & Onde? & Onde a ação será executada? \\
\cline { 2 - 4 } & When? & Quando? & Quando a ação será executada? \\
\cline { 2 - 4 } & Why? & Por quê? & Por que executar a ação? \\
\hline \multirow{2}{*}{$\mathbf{2 H}$} & How? & Como? & Como a ação será executada? \\
\cline { 2 - 4 } & How Much? & Quanto custa? & Quanto custa para executar? \\
\hline
\end{tabular}

Fonte: Adaptado de Meira, 2003

\subsubsection{Lista de Verificação (Check list)}

Segundo Carpinetti (2012) A folha de verificação é uma ferramenta da qualidade utilizada para o planejamento e coleta de dados, visualizando de forma simples e organizada os dados que precisam ser observados, de modo geral esta ferramenta é utilizada para determinar circunstâncias de não conformidades como defeitos, falhas ou quebra de máquinas/equipamentos. Os procedimentos para elaboração de uma folha de verificação se iniciam a partir da identificação do problema ou itens a serem analisados, o passo posterior é a construção de uma tabela contendo esses dados, onde irá conter os problemas, defeitos ou falhas, assim como também haverá colunas com os períodos de tempo nos quais os problemas ocorrem.

\subsubsection{Fluxograma de processo}

De acordo com Campos (1992), o fluxo de processo é indispensável para a padronização e consequente entendimento do processo, sendo este um facilitador a identificação ou visualização dos produtos produzidos, dos clientes e fornecedores internos e externos do processo, das funções, das responsabilidades e dos pontos críticos.

Segundo Slack (2002), o fluxograma de processo é uma ferramenta gráfica que possibilita o sequenciamento de uma determinada atividade. Ao se elaborar um fluxograma faz-se necessário levar em consideração os seguintes passos:

- Definir todos os componentes que irão participar do processo;

- Definir o escopo do processo;

- Realizar a representação simbólica dos elementos constituinte do processo de maneira correta;

- Conectar de maneira correta os processos com auxílios de setas, demonstrando a direção do fluxo de informação. 


\subsection{A IMPORTÂNCIA DAS FERRAMENTAS DA QUALIDADE PARA GESTÃO DE PROCESSOS}

As ferramentas da qualidade são de suma importância para gestão de processo, pois a partir das mesmas é possível identificar as causas que provocaram o efeito indesejado e determinar os pontos de controle para conter as mesmas (CAMPOS, 2004).

Segundo Campos (2004), para que se tenha excelência no gerenciamento de um processo, faz-se necessário determinar pontos de controle e suas respectivas metas, para garantir a melhoria contínua dos mesmos. duas ações:

Para Antunes (2008), a melhoria de um processo pode ser constatada a partir de

- Análise sistêmica do sistema produtivo: consiste na verificação dos pontos que impedem o fluxo de processo e o aumento da produção;

- Redução sistemática dos tempos de atravessamento: consiste na análise e compreensão e redução da espera nos sistemas produtivos.

\subsection{QUALIDADE NA PRESTAÇÃO DE SERVIÇO}

Segundo Oliveira (2006), para que as organizações se mantenham estáveis em um mercado amplamente competitivo faz-se necessário que a mesmas foquem no desenvolvimento da qualidade de seus produtos e serviços.

Para Godói et al (2009), o conceito de qualidade está relacionado não somente a busca da satisfação dos clientes de um produto ou serviço, mas também a todas entidades fundamentais a existência e a excelência organizacional da instituição.

A estruturação e o funcionamento de um processo de gestão da qualidade voltado para prestação de serviços estão baseados em um conjunto referencias que auxiliam nas ações a serem tomadas, para que se atendam os conceitos de qualidade adotados pela organização (PALADINI, 2009).

\section{METODOLOGIA}

Este estudo pode ser classificado como um estudo de caso, pois objetiva estudar a viabilidade da utilização de ferramentas da qualidade para melhoria na gestão de processos em oficina mecânica localizada no município do Rio de Janeiro (TURRIONI E MELLO, 2012).

Com relação à natureza, esta pesquisa pode ser classificada como qualitativaquantitativa, pois ao mesmo tempo que visa qualificar os processos desenvolvidos pela oficina, também tende a quantificar os problemas enfrentados pela mesma (GIL, 2008).

Para que os objetivos sejam alcançados, faz-se necessária a elaboração das ações a serem tomadas. Para isto, é primordial a combinação de ferramentas de qualidade para definição destas ações.

Neste estudo de caso, a metodologia adotada é composta pelo ciclo PDCA atrelado à utilização das seguintes ferramentas da qualidade:

- Coleta de dados a fim de realizar uma pesquisa de satisfação;

- Brainstorming, para levantamento dos problemas mecânicos de maior incidência na oficina;

- Diagrama de Ishikawa, visando identificar as causas de retrabalho;

- Plano de Ação $(5 \mathrm{WlH})$, para direcionar as ações a serem executadas para a melhoria dos serviços prestados;

- A Lista de Verificação promovendo a padronização dos procedimentos de análise prévia a serem realizados pelos colaboradores; 
- Fluxograma, almejando mapear os processos desenvolvidos pela empresa de modo a promover uma padronização dos mesmos.

Vale ressaltar que como o objetivo deste estudo é a melhoria dos serviços prestados pela oficina, os custos das ações executadas não serão mensuradas.

\section{ANÁLISE E DISCUSSÕES}

\subsection{PLANEJAMENTO (PLAN)}

É imprescindível que todas as medidas definidas na fase de planejamento sejam aplicadas minuciosamente conforme o planejado. Caso contrário, não poderá ser comprovado que os resultados obtidos no fim do ciclo foram resultantes das mudanças sugeridas.

\subsubsection{Pesquisa de opinião}

Nesta etapa do estudo foi aplicado um questionário contendo cinco perguntas, sendo três fechadas e duas abertas, relacionadas a problemas dos clientes com a empresa, a fim de coletar dados referentes à insatisfação dos mesmos. Esta análise foi realizada no período de dois meses, contando com a participação de sessenta clientes, conforme a Figura 2 a seguir.

Figura 2: Questionário para pesquisa de opinião

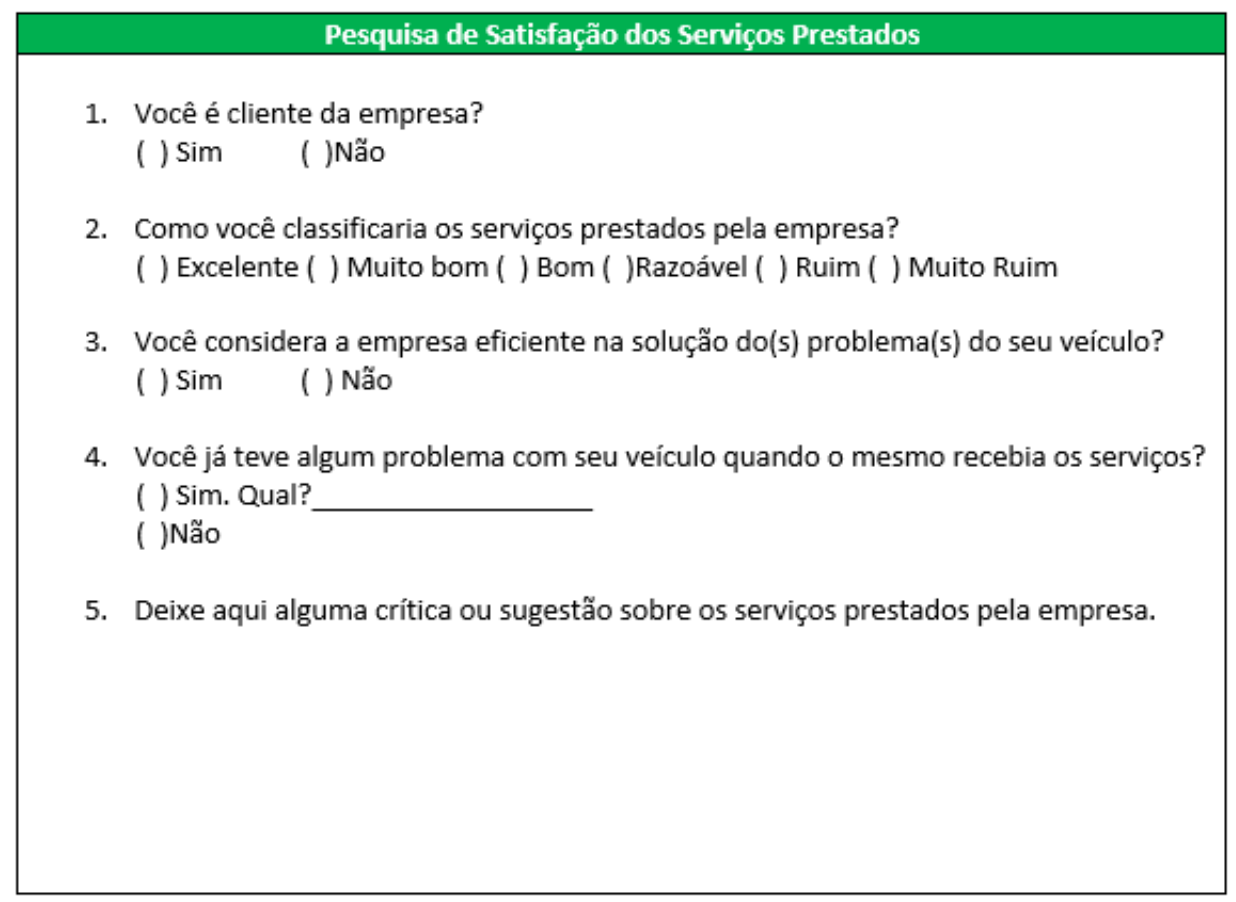

Fonte:Autores, 2019

A partir dos dados levantados, foi possível fazer as seguintes considerações: no primeiro mês, observou-se que quinze clientes alegaram outros defeitos mecânicos em seus automóveis, diferentes dos que solicitaram conserto, nove clientes alegaram outros problemas (danos ao veículo e/ou itens faltosos) e nove alegaram não ter qualquer problema. No segundo mês, vinte clientes alegaram outros defeitos mecânicos em seus automóveis, não sendo os que solicitaram conserto, dois alegaram outros problemas (danos ao veículo e/ou 
itens faltosos) e cinco clientes alegaram não ter qualquer problema, como mostra o Gráfico 1 a seguir.

Gráfico 1: Índice de reclamação antes da implementação do projeto

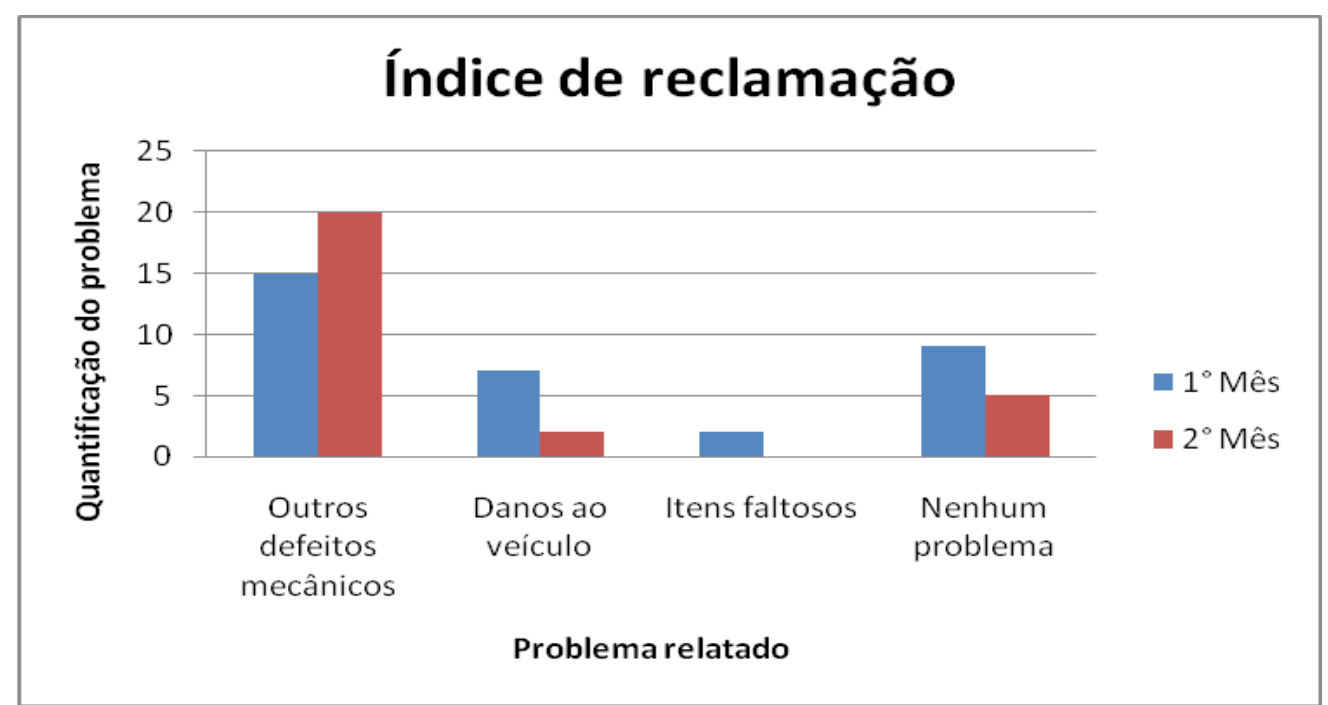

Fonte: Autores, 2019

\subsubsection{Brainstorming}

Nesta fase foi realizada uma reunião com os colaboradores da empresa, a partir da pesquisa de opinião inicialmente aplicada, visando o levantamento das possíveis falhas no gerenciamento de seus processos, que vinham ocasionando os problemas enfrentados pela oficina. Ao término desta reunião, os funcionários chegaram à conclusão que os problemas eram provenientes da ausência de padronização e controle da qualidade dos serviços prestados.

\subsubsection{Diagrama de Ishikawa}

Após análise das etapas anteriores, verificou-se que o maior índice de reclamação dos clientes é a respeito de defeitos mecânicos presentes no veículo diferentes dos solicitados inicialmente para reparo e outros problemas relacionados a danos ao automóvel e/ ou à falta de itens contidos no mesmo quando deixados no pátio da oficina. Em vista destes empecilhos, foram elaborados dois Diagramas de Ishikawa para verificação das possíveis causas de retrabalho e da insatisfação dos clientes, representados pelas Figuras 3, 4 e 5 a seguir.

Figura 3: Diagrama de Ishikawa para causas de clientes insatisfeitos com outros problemas

Método

Falta de checagem prévia mecânico

Falta de controle da qualidade nos serviços prestados

Clientes insatisfeitos com outros problemas mecânicos 
Figura 4: Diagrama de Ishikawa para as causas de clientes insatisfeitos por danos ao veículo

Método

Falta de checagem prévia

Falta de treinamento adequado
Falta de controle da qualidade nos serviços prestados
Clientes insatisfeitos com danos ou itens faltosos no veículo

Mão de obra

Fonte: Autores, 2019

Figura 5: Diagrama de Ishikawa para as causas de retrabalho

Método

Falta de padronização dos

serviços prestados

Falta de controle da qualidade nos serviços prestados

Falta de checagem prévia

Retrabalho com outros problemas mecânicos

Falta de treinamento adequado

Mão de obra

Fonte: Autores, 2019 


\subsection{EXECUTAR $(D O)$}

Na segunda etapa são postas em prática todas as medidas adotadas no planejamento, controlando-se todas as ações e seguindo os passos de acordo com o proposto. Nessa fase, adotou-se uma sequência padronizada de testes. A partir da análise do Diagrama de Ishikawa, foi traçado um Plano de Ação para servir de apoio à proposição de possíveis soluções para o problema de maior incidência na oficina. Como o foco deste estudo é a padronização dos processos visando a qualidade dos serviços oferecidos pela oficina, os custos não serão mensurados. Desta forma, a ferramenta utilizada no Plano de Ação será o $5 \mathrm{~W} 1 \mathrm{H}$, ilustrado no Quadro 2 a seguir.

Quadro 2: Plano de Ação 5W1H

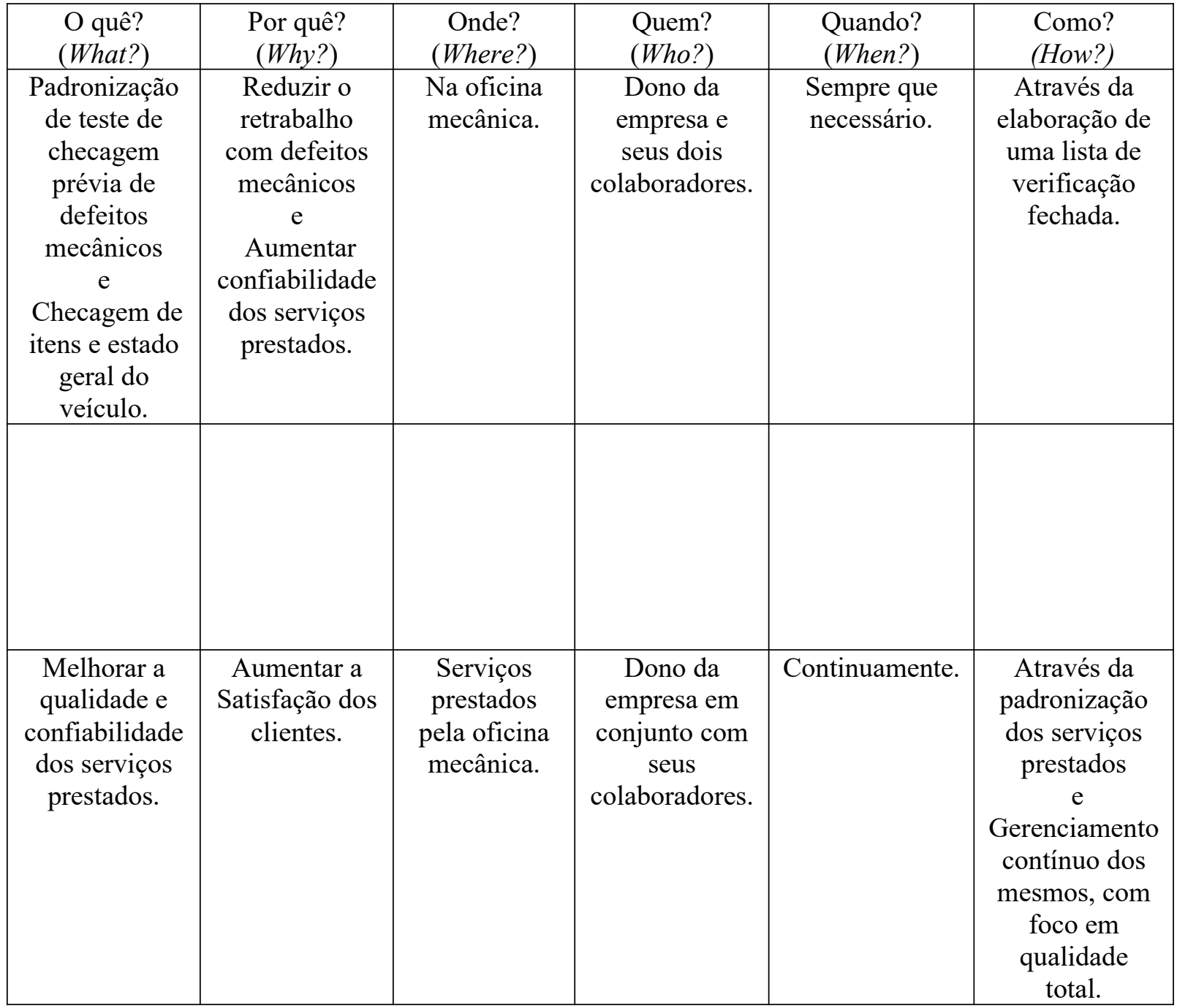

Autores, 2019

Paralelamente, elaborou-se uma Lista de Verificação prévia, Figura 6, na qual o automóvel será analisado quanto ao seu estado de entrada na oficina. Serão inspecionados itens como pintura, estado dos pneus, presença de itens obrigatórios, itens pessoais, dentre outros, evitando prejuízos ao relacionamento com o requisitante. Além disso, constarão 
nessa lista os procedimentos de testes a serem realizados, de modo sequenciado, previamente ao início da manutenção do veículo como mostram a seção Testes prévios também apresentados na Figura 6 a seguir.

Figura 6: Lista de verificação para padronização de processos

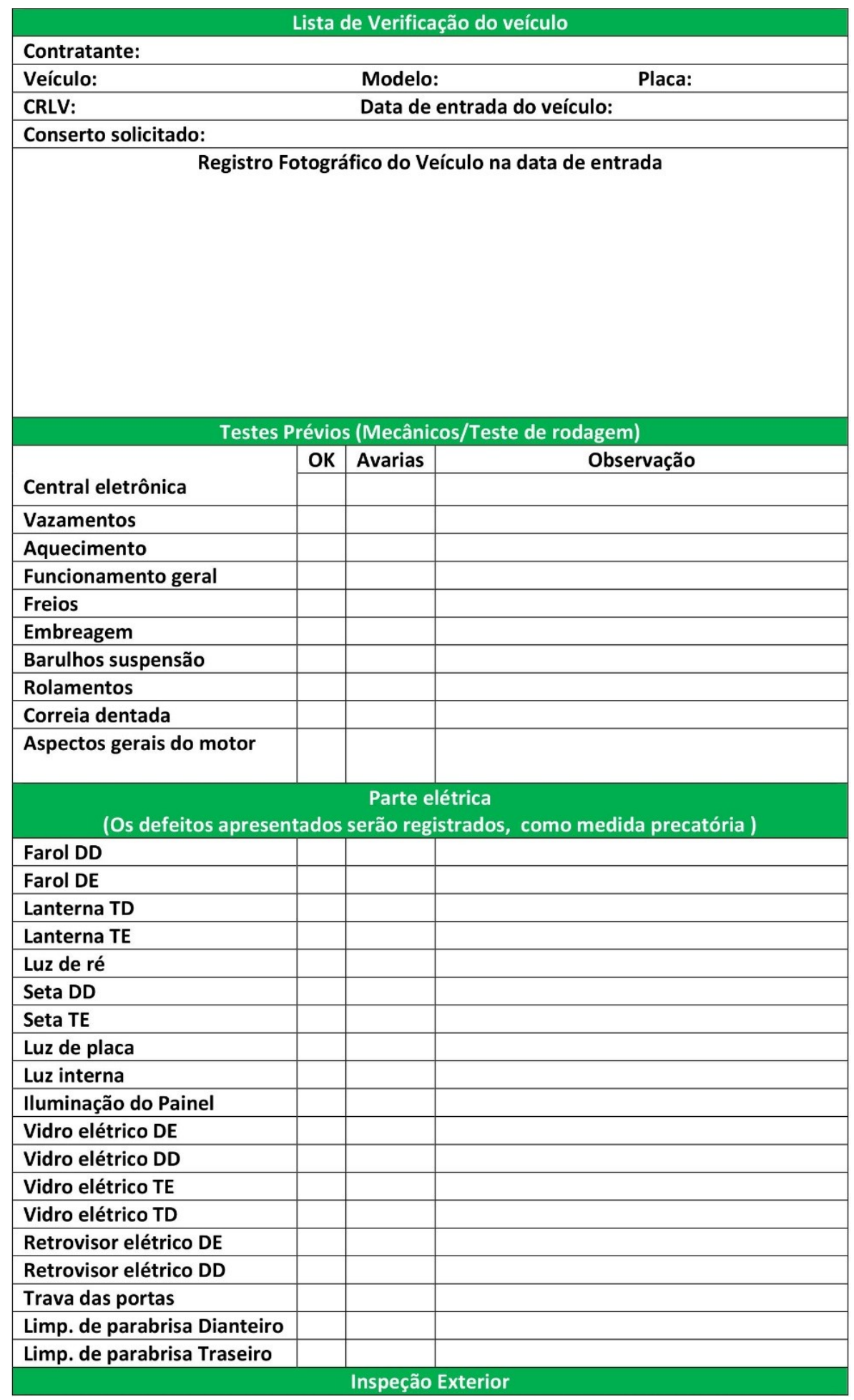




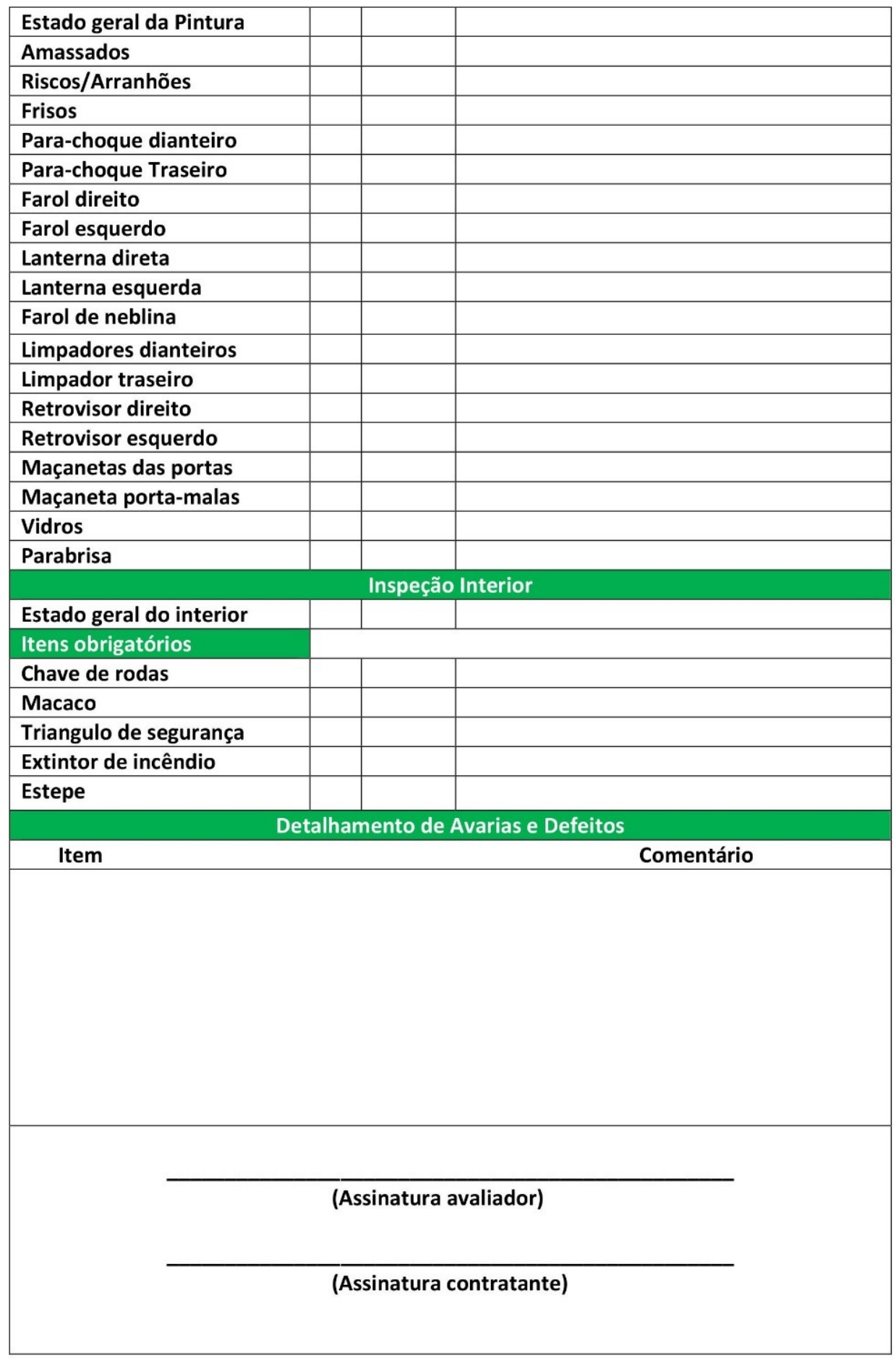

Fonte: Autores, 2019

\subsection{CHECAR (CHECK)}

$\mathrm{Na}$ fase de checar do ciclo, foram verificados os resultados obtidos após a aplicação das medidas para assegurar que as ações propostas estão sendo cumpridas conforme o estabelecido. Faz-se necessário que a Lista de Verificação seja atualizada sempre que surgirem novas tecnologias de identificação de problemas veiculares e lançamentos de novos acessórios automobilísticos. Além disso, um fator a ser checado continuamente é satisfação do cliente em relação aos serviços prestados, realizando uma pesquisa de opinião 
periodicamente de modo que o estabelecimento possa constantemente aprimorar seus procedimentos.

A variável utilizada para observação da eficiência do processo foi o índice de reclamações, que foi medido no intervalo de tempo de meses, e com a participação de trinta entrevistados, com auxílio do mesmo questionário utilizado na coleta de dados inicial disposto na Figura 1.O Gráfico 2 a seguir uma comparação do índice de reclamação antes e depois da implementação das ferramentas da qualidade para melhoria das gestão dos serviços prestados pela oficina.

Gráfico 2:Comparação do índice de reclamação

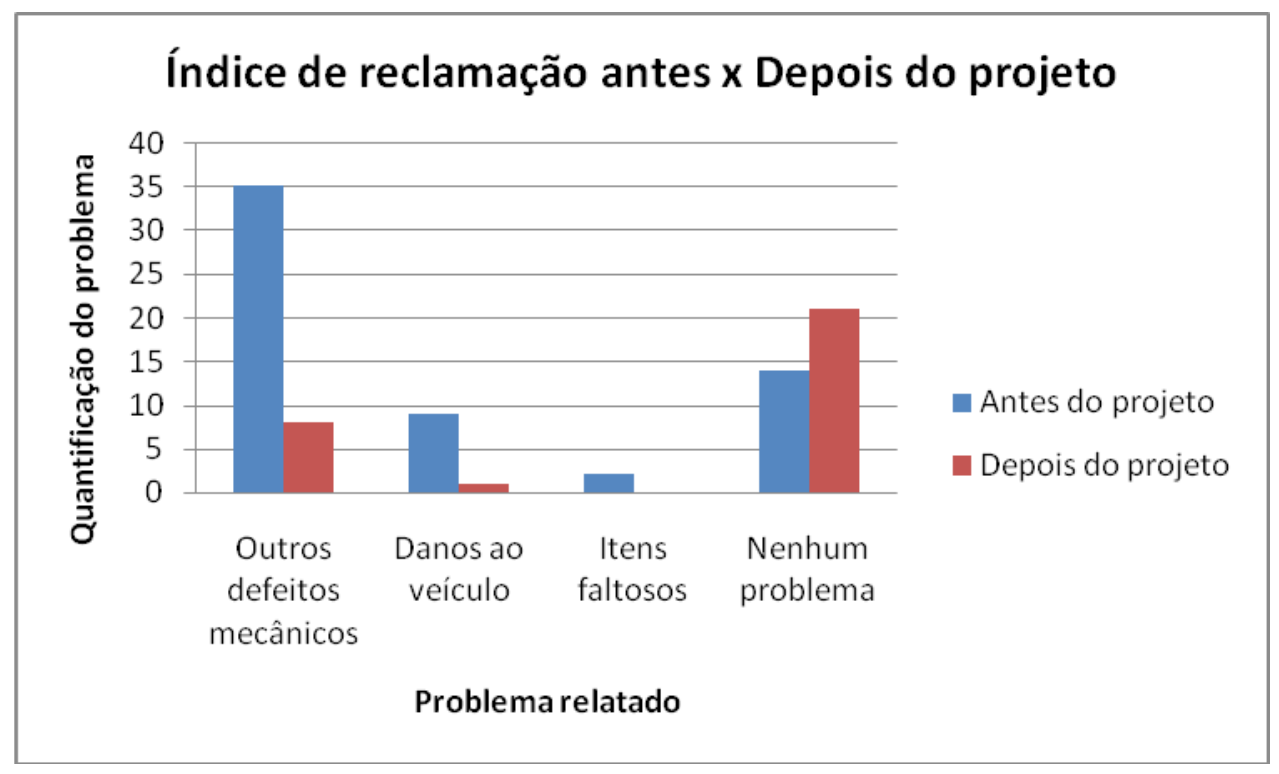

Fonte: Autores, 2019

Com base na análise realizada a partir do Gráfico 2, foi possível observar que o índice de reclamação com outros defeitos mecânicos reduziu $77,14 \%$, já as reclamações com danos ao veículo reduziram $88,89 \%$, com relação as reclamações relacionadas a itens faltosos no veículo, estas tiveram uma redução de $100 \%$.

\section{4. $\quad \operatorname{AGIR}(A C T)$}

A última fase consiste na padronização dos serviços prestados pela empresa. Com base na Lista de Verificação gerada, e nos resultados obtidos, que foram considerados satisfatórios, elaborou-se o fluxo de processos da oficina após as melhorias implementadas, conforme a Figura 7 a seguir. 
Figura 7: Fluxograma de processo após melhoria

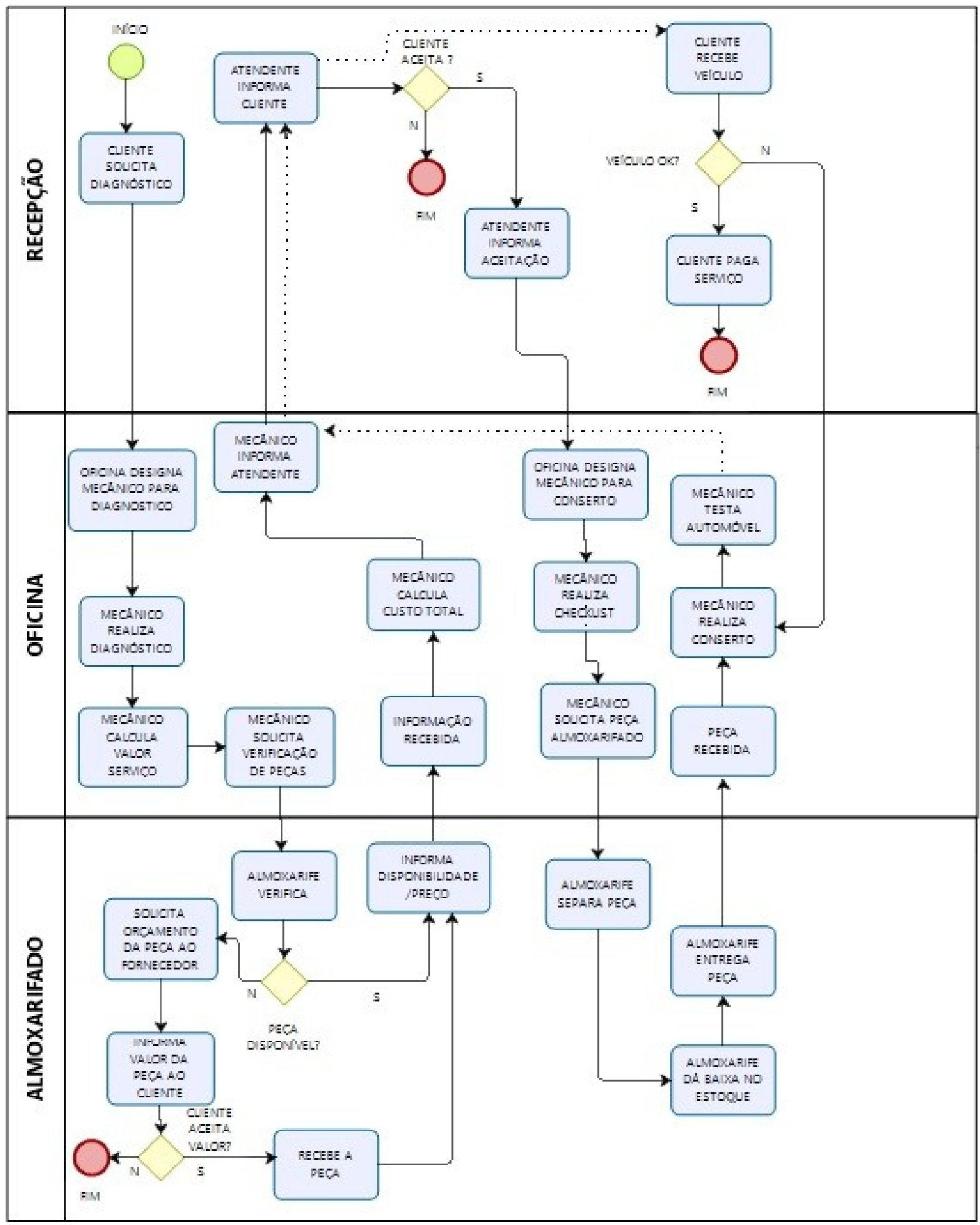

Fonte: Autores, 2019

\section{CONCLUSÃO}

Este artigo baseia-se nos índices de reclamação dos clientes em relação aos serviços oferecidos pela oficina e suas causas, superando-os através da implementação conjunta de 
ferramentas da qualidade. O presente estudo de caso denota a relevância da padronização dos processos para a obtenção de melhorias no desempenho da empresa. Por meio da aplicação da metodologia proposta, foram reduzidos o índice de retrabalho com outros problemas mecânicos em $77,14 \%$, assim como os índices de reclamações com danos e itens faltosos no veículo reduziram respectivamente $88,89 \%$ e $100 \%$. Deste modo, podemos verificar que o Ciclo PDCA utilizado em conjunto com outras ferramentas da qualidade reduziu os problemas enfrentados pela empresa, contribuindo assim, para um retorno positivo sobre os serviços prestados, e para a padronização das ações a serem executadas na prestação de serviços, o que influi diretamente na redução de falhas geradas dentro do processo, e na maior satisfação dos clientes com a empresa estudada.

\section{BIBLIOGRÁFICAS}

ANTUNES, Junico. Sistemas de Produção: conceitos e práticas para projetos e gestão da produção enxuta. 1. ed. Porto Alegre, RS: Bookmann, 2008.

BATISTA, D. S.; GOIS, J. V.; Busca da melhoria produtiva com auxílio de algumas das ferramentas da qualidade: estudo de caso realizado em uma indústria de confecção. Anais eletrônicos da ABEPRO, 2013, Salvador.

CAMPOS, V. F. TQC - Controle da qualidade total: no estilo japonês. Minas Gerais: $5^{\circ}$ ed., 1992.

CAMPOS, V. F. Gerenciamento da rotina do trabalho do dia-a-dia. Nova Lima MG: INDG Tecnologia e Serviços Ltda, 2004

CAMPOS, V. F. Gerenciamento pelas diretrizes. 4 ed. Belo Horizonte: Editora de Desenvolvimento Gerencial,2004.

CARPINETTI, L. C. R. Gestão da qualidade: Conceitos e Técnicas. 2 ed. São Paulo: Atlas, 2012.

JUNIOR, E.L.C., Gestão em processos produtivos, Curitiba: Ibpex, 2008.

MEIRA, R. C. As ferramentas para a melhoria da qualidade.2. Ed. Porto Alegre: SEBRAE/RS, 2003.

MIGUEL, P. A. C. Qualidade: enfoques e ferramentas. São Paulo: Arttliber Editora, 2001.

OLIVEIRA, O. J.; et al. Gestão da qualidade: Tópicos avançados. São Paulo: Thomson Pioneira, 2006.

GIL, A. C. Como elaborar projetos de pesquisa. 4. Ed. São Paulo: Atlas, 2008.

GODÓI A.T. et al A Utilização Da Qualidade No Marketing Empresarial: Auto Posto Lins Ltda, 2009 Monografia. (Curso de Administração) - Centro Universitário Católico Salesiano Auxilium. Lins.

LISBÔA, M. G. P.; GODOY, L. P. Aplicação do método 5w2h no processo produtivo do produto: a joia. Iberoamerican Journal of Industrial Engineering, v.4, n. 7, 2012, p. 32-47.

PALADINI, E. P. Gestão da Qualidade: Teoria e Prática. 2. ed. São Paulo: Atlas, 2009.

ROTH, C. W. Qualidade e Produtividade. e-Tec Brasil. $3^{\text {a }}$ ed. Colégio Técnico Industrial, UFSM, Santa Maria, 2011. 
SILVEIRA, H. E.; MARTELLI, R.; OLIVEIRA V. V. A implantação da ferramenta 5W2H como auxiliar no controle da gestão da empresa agropecuária São José. Revista de Administração do Sul do Pará: FESAR. v. 3, n. 2, Mai/Ago, 2016.

SLACK, N.; CHAMBERS, S.; JOHNSTON, R. Administração da produção. 2 Ed. São Paulo: Atlas, 2002.

TURRIONI, J. B.; MELLO, C. H. P. Metodologia de pesquisa em engenharia de produção: estratégias, métodos e técnicas para condução de pesquisas quantitativas e qualitativas. Universidade Federal de Itajubá, Programa de pós-graduação em engenharia de produção, curso de especialização em qualidade e produtividade, Itajubá, 2012.

WERKEMA, M. C. C. Ferramentas Estatísticas Básicas para o Gerenciamento de Processos.V.2. Fundação Christiano Ottoni. Escola de Engenharia da UFMG. Belo Horizonte, MG. 1995. 